\title{
Sodium tanshinone IIA sulfonate depresses angiotensin II- induced cardiomyocyte hypertrophy through MEKJERK pathway
}

Le Yang ${ }^{1 *}$, Xiaojing Zou ${ }^{2 *}$, Qiansheng Liang ${ }^{1,4}$, Hao Chen ${ }^{3}$, Jun Feng', Li Yan', Zhaohua Wang', Daixing Zhou', Shusheng $\mathrm{Li}^{1}$, Shanglong $\mathrm{Yao}^{2}$ and Zhi Zheng ${ }^{1}$

\author{
${ }^{1}$ Department of Emergency Medicine \\ Tongji Hospital, Tongji Medical College \\ Huazhong University of Science and Technology \\ 1095 Jiefang Avenue, Wuhan \\ Hubei 430030, P.R.China \\ ${ }^{2}$ Department of Anesthesiology \\ Union Hospital, Tongji Medical College \\ Huazhong University of Science and Technology \\ 1277 Jiefang Avenue, Wuhan \\ Hubei 430022, P.R.China \\ ${ }^{3}$ School of Medicine and Health Administration \\ Tongji Medical College \\ Huazhong University of Science and Technology \\ 13 Hangkong Road, Wuhan \\ Hubei 430030, P.R.China \\ ${ }^{4}$ Corresponding author: Tel, 86-27-65060956; Fax, 86-27-83662660 \\ E-mail, Iqstjmu@yahoo.com.cn \\ *The first two authors contributed equally to this work.
}

Accepted 11 December 2006

Abbreviations: Ang II, angiotensin II; ANP, atrial natriuretic peptide; ERK, extracellular signal-regulated kinase; SBP, systolic blood pressure; STS, Sodium tanshinone IIA sulfonate

\begin{abstract}
Cardiomyocyte hypertrophy is a major cause of morbidity and mortality worldwide. The aim of this study is to determine the effects of sodium tans hinone IIA sulfonate (STS) on cardiomyocyte hypertrophy induced by angiotensin II (Ang II) in vivo and in vitro. In long-term treatment, adult Wistar rats were infused with Ang II for three weeks via osmotic mini-pumps and some of them were given intragas trically of STS. Left ventricle was isolated; the ratio of left ventricular weight to body weight and systolic blood pressure (SBP) were determined and heart morphometry was assessed after hematoxylin and eosin staining. Results indicated STS inhibited Ang Il-induced increases in myocyte diameter and
\end{abstract}

decreased the LVW/BW ratio independent of de creasing systolic blood pressure. In vitro, treatment of cultured cardiomyocytes with STS inhibited Ang Il-induced increase in cell size, protein synthesis, ANP expression, activation of extracellular signalregulated kinase (ERK) and ERK kinase (MEK). Then we reexamined the mechanism of STS-induced antihypertrophic effects. Results revealed MEK inhibitor U0126 $(20 \mu \mathrm{M})$ markedly enhanced STS-induced depressions in $\left[{ }^{3} \mathrm{H}\right]$ leucine incorporation and ANP expression. In conclusion, MEK/ERK pathway plays a significant role in the anti-hypertrophic effects of STS.

Keywords: angiotensin II; extracellular signal-regulated MAP kinases; hypertrophy; myocytes, cardiac; tanshinone

\section{Introduction}

Cardiomyocyte hypertrophy, a common complication of hypertension, increases the risk for cardiac ischemia, left ventricular dysfunction and sudden cardiac death; represents a very strong predictor of cardiovascular mortality and death of all causes and is recognized as a risk factor for the development of congestive heart failure (Levy et al., 1990). One of the most important factors contributing to the development of cardiomyocyte hypertrophy is angiotensin II (Ang II) which increases protein synthesis and cell diameter in cultured neonatal rat myocytes through the type 1 Ang II receptor (Baker et al., 1990). These processes directly lead to cardiomyocyte hypertrophy .

Ang II is a multifunctional agonist for cardiomyocyte hypertrophy, stimulating protein phosphorylation, contractility, gene expression and cell growth (Kagiyama et al., 2002). Many of the signaling events stimulated by Ang II are mediated by members of the mitogen-activated protein kinase (MAPK) family, including the extracellular signal-regulated kinase (ERK), the p38 and the c-Jun NH2-terminal kinase (JNK) (Thorburn et al., 1995). Among the MAPKs, ERK has been focused on the essential regulators of a hypertrophic response although JNK and p38 were recently studied in regulating cardiac hypertrophy (Sugden, 2001; Maller, 2003; Ptashne 
and Gann, 2003).

Sodium tanshinone IIA sulfonate (STS) is a derivative of tanshinone IIA which is a lipid-soluble pharmacologically active component isolated from the rhizome of the Chinese herb Salvia miltiorrhiza, a well-known traditional Chinese medicine used for the treatment of cardiovascular diseases such as coronary heart disease (Zhao et al., 1996). In this paper, we used long-term treatment experiments and cultured neonatal rat cardiomyocytes to investigate the influence of STS on Ang II-induced cardiomyocyte hypertrophy in vivo and in vitro; examined effects of STS on MEK/ERK signaling pathway; then raised the experimental basis for using STS to cardiomyocyte hypertrophy in clinic.

\section{Materials and Methods}

\section{Materials}

Adult Wistar rats (200-230 g) and 1-day-old Wistar rats were obtained from Experimental Animal Center of Tongji Medical College, Grate II, and Certificate No 19-050. This study complies with the European Community Guidelines for the Care and Use of Experimental Animals and was approved by the Animal Research Committee of Tongji Medical College of Huazhong University of Science and Technology (Wuhan, China). STS (99.5\%) were obtained from the Research Center of Traditional Chinese Medicine (Wuhan, China) and dissolved in PBS. Ang II was obtained from Sigma-Aldrich (Saint Louis). U0126 was obtained from Alexis Biochemicals (Lausen, Switzerland). Antibodies for phosphorylated ERK, MEK and $\alpha$-actin were purchased from Santa Cruz Biotechnology Inc (CA). Texas Red-X phalloidin was obtained from Molecular Probes Inc. All other chemicals used were of the highest grade available commercially. The molecule structure of STS is shown in Figure 1.

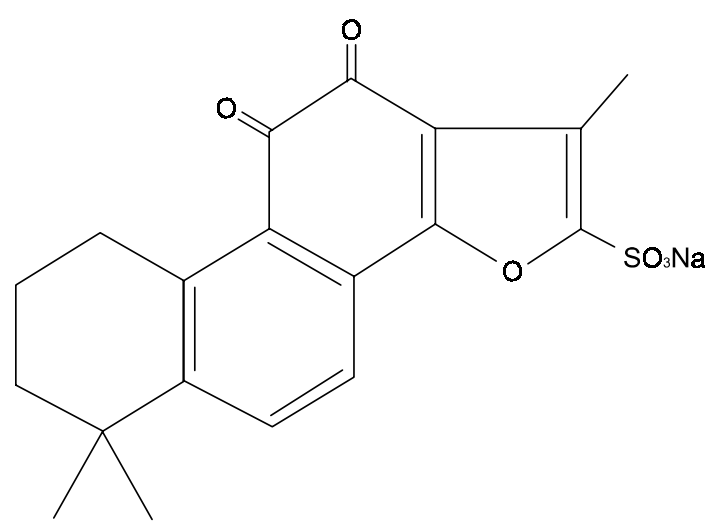

Figure 1. The molecular structure of STS.
Experimental protocol in long-term treatment For Ang II stimulation, adult Wistar rats weighing 200 to $230 \mathrm{~g}$ were anesthetized with isoflurane. Osmotic mini-pumps (Alza Corp.) containing either saline or Ang II (25 $\mathrm{ng} / \mathrm{kg} / \mathrm{min}$, dissolved in saline), were implanted subcutaneously for three weeks. Some Ang II-exposed rats were given intragastrically of PBS, others were given intragastrically of STS (50 $\mathrm{mg} / \mathrm{kg} / \mathrm{d}$ ) in PBS for 3 weeks. At the end of experiments, morphology of left ventricle was examined.

\section{Determination of systolic blood pressure}

In all rats, systolic blood pressure (SBP) was measured by the tail-cuff method using the plethysmographic tail-cuff method. The blood pressure was measured twice a week in each rat by the same person and at the same time of day (Sen, 1983).

\section{Morphological examination}

After 3 weeks of the treatment, animals were weighed and killed by decapitation. The thoracic cavity was immediately opened. With the blood squeezed out, the heart was excised and rinsed in cold physiological saline. The atria were removed and all the epicardial fat was removed. The left ventricle was isolated, blotted, and weighed in an analytical balance. The hypertrophy index was determined using the ratio of left ventricular weight over body weight (LVW/BW) (Hayakawa and Raij, 1997). Histopathological observation was also carried out as described previously (Miao et al., 2001). Briefly, immediately after gross detection, all samples of left ventricles in 2- to 3-mm-thick slices were immersed in formalin solution for more than 1 week, dehydrated in ethanol, cleared in dimethylbenzene, and embedded in paraffin. Then the 5 - $\mu \mathrm{m}$-thick sections were prepared and stained with hematoxylin and eosin for light microscopic evaluation. Mean myocyte diameter was calculated by measuring 100 cells from sections stained with hematoxylin and eosin.

\section{Neonatal cardiomyocyte cultures}

Primary cultures of 1-day old neonatal Wistar rat myocytes were prepared as previously described (Hannan et al., 1996). Minced ventricular myocardium was placed into D-Hanks' salt solution, $\mathrm{pH}$ 7.4. The cells were dissociated by a trypsin $(0.125 \%)$ digestion in D-Hanks' salt solution. After each of five successive $8 \mathrm{~min}$ incubations, the dissociated cells were mixed with DMEM containing $10 \%$ FBS and were centrifuged and pooled. The dissociated cells were enriched for cardiomyocytes by the technique 
of differential adhesion for $90 \mathrm{~min}$ and plated at a concentration of $10^{6}$ cells/well. Cultures were incubated in a humidified $5 \% \mathrm{CO}_{2}-95 \% \mathrm{O}_{2}$ at $37^{\circ} \mathrm{C}$. Bromodeoxyuridine $(0.1 \mathrm{mM})$ was added into the medium to inhibit proliferation of nonmyocytes. This procedure yielded cultures with $90-95 \%$ myocytes, as assessed by microscopic observations of cellular contractions. After a 2 overnight incubation in DMEM containing $10 \%$ FBS the attached cells were rinsed and maintained in DMEM containing $0.1 \%$ FBS. After $48 \mathrm{~h}$ of serum starvation, cardiomyocytes were treated with various agents.

\section{Immunofluorescence}

After treated with $0.1 \mu \mathrm{M}$ Ang II alone or with $10 \mu \mathrm{M}$ STS for $24 \mathrm{~h}$, cardiomyocytes were fixed in 3.7\% paraformaldehyde, and permeabilized with $0.3 \%$ Triton X-100. Cells were incubated with Texas Red$X$ phalloidin (1:500). Immunostained cardiomyocytes were viewed by fluorescence microscopy. Quantitation of cell surface area was performed on actin-stained cardiomyocytes. The cell size of cardiomyocytes was measured by directly tracing the stained areas on a photograph.

\section{Protein synthesis measurement $\left(\left[{ }^{3} \mathrm{H}\right]\right.$ Leucine incorporation)}

Protein synthesis was determined by assessing the incorporation of labelled leucine from the extracellular medium into total TCA-precipitable cell proteins (Yamazaki et al., 1995). Cardiomyocytes cultured for $48 \mathrm{~h}$ in DMEM with $10 \%$ FBS were starved in $0.1 \%$ FBS-DMEM for $24 \mathrm{~h}$. Then, cells were treated with $0.1 \mu \mathrm{M}$ Ang II alone or with STS (2, 10, $50 \mu \mathrm{M})$ for $24 \mathrm{~h}$. $\left[{ }^{3} \mathrm{H}\right]$ Leucine $(1 \mu \mathrm{Ci} / \mathrm{ml})$ was added $2 \mathrm{~h}$ before harvest. At the end of the labeling incubation, plates were placed on ice, quickly washed twice with ice-cold phosphate-buffered saline, incubated for $30 \mathrm{~min}$ with $5 \% \mathrm{TCA}$, and washed again. Precipitates were solubilized for $30 \mathrm{~min}$ in 0.5 $\mathrm{M} \mathrm{NaOH}$ and neutralised. Radioactivity was measured by a liquid scintillation counter.

\section{Northern blot analysis}

After a $24 \mathrm{~h}$ incubation with various agents, the cultured myocytes were submitted to RNA extraction. Total RNA was extracted from cultured cells with TRIzol Reagent (Sigma Chemical Co.). Northern blot analysis was performed according to the procedure previously described (Wollert et al.,1994). The cDNA probes used were as follows: rat atrial natriuretic peptide $(A N P)$ cDNA, a 0.825-kb fragment and rat $\mathrm{GAPDH}$, a 1.3-kb fragment. The cDNA probes were labeled with $\left[{ }^{32} \mathrm{P}\right] \mathrm{dCTP}(3 \mathrm{mCi} / \mathrm{mmol}$;
New England Nuclear) by random primer extension. Autoradiography was performed on a Kodak XAR-5 film with an intensifying screen at $-80^{\circ} \mathrm{C}$. Autoradiograms were quantified by an image analyzer (LEICA, DC200, Germany). Results were normalized to GAPDH gene expression.

\section{Western blot analysis}

To explore the molecular mechanisms of the antihypertrophic effect of STS, we determined whether STS inhibits signaling through MEK/ERK pathway. After various treatments, myocytes were harvested and lysed for $20 \mathrm{~min}$ in $200 \mu \mathrm{l}$ lysis buffer $(10 \mathrm{mM}$ Tris- $\mathrm{HCl}, 0.5 \% \mathrm{NP} 40,150 \mathrm{mM} \mathrm{NaCl}, 1 \mathrm{mM} \mathrm{Na}_{3} \mathrm{VO}_{4}$, $10 \mathrm{mM} \mathrm{NaF}, 1 \mathrm{mM}$ PMSF, $1 \mathrm{mM}$ EDTA, $10 \mu \mathrm{g} / \mathrm{ml}$ aprotinin, $10 \mu \mathrm{g} / \mathrm{ml}$ leupeptin and $1 \mu \mathrm{g} / \mathrm{ml}$ pepstatin). Equal protein was loaded in each lane, resolved by SDS-PAGE, blotted on nitrocellulose membrane. Membranes were blocked in $5 \%$ nonfat milk powder in Tris-buffered saline (TBS)/0.1\% Tween-20 for $1 \mathrm{~h}$ at room temperature, and then incubated with specific antibodies in 5\% BSA in TBS for another $1 \mathrm{~h}$. Membranes were incubated with peroxidase conjugated second antibody in blocking buffer for $1 \mathrm{~h}$. The labeled proteins were detected with enhanced chemiluminescence.

\section{Statistical analysis}

Results were expressed as mean \pm S.D. Statistical significance was determined using one-way ANOVA. The differences were considered statistically significant at a value of $P<0.05$.

\section{Results}

\section{Effects of STS on Ang II-induced left ventricular hypertrophy}

After 3 weeks of experiment, Ang II rats exhibited left ventricular hypertrophy, as evidenced by the increase of the LVW/BW ratio, when compared with controls (Figure 2). Meanwhile, there were significant differences in the LVW/BW ratio between STS-treated and untreated Ang II rats. In STStreated Ang II rats, the LVW/BW ratio was decreased compared with untreated Ang II rats, and similar to the levels in control. However, there was no obvious difference in SBP between STS-treated and untreated Ang II rats, which means anti-hypertrophic effect of STS is independent of decreasing SBP. Under microscope, left ventricular tissues from Ang II-treated rats demonstrated obvious cardiomyocyte hypertrophy (Figure 3 ). These characteristic changes induced by Ang II were markedly inhibited by long-term treatment of STS. 
A

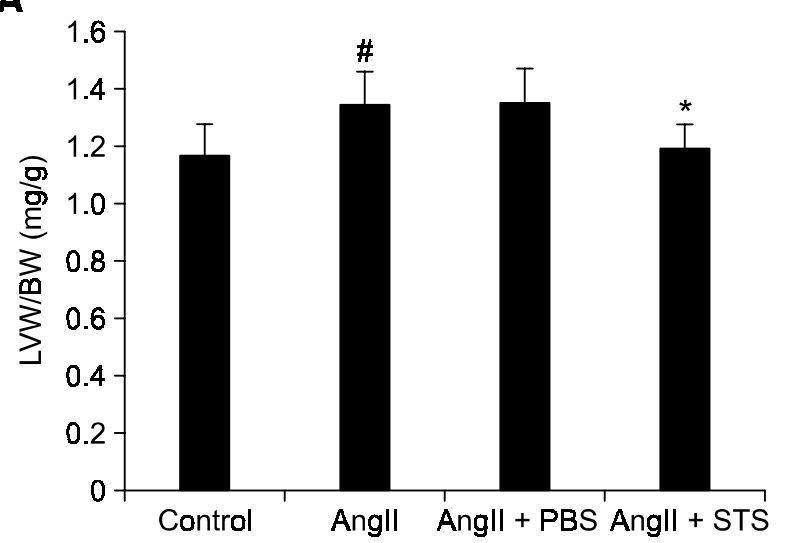

B

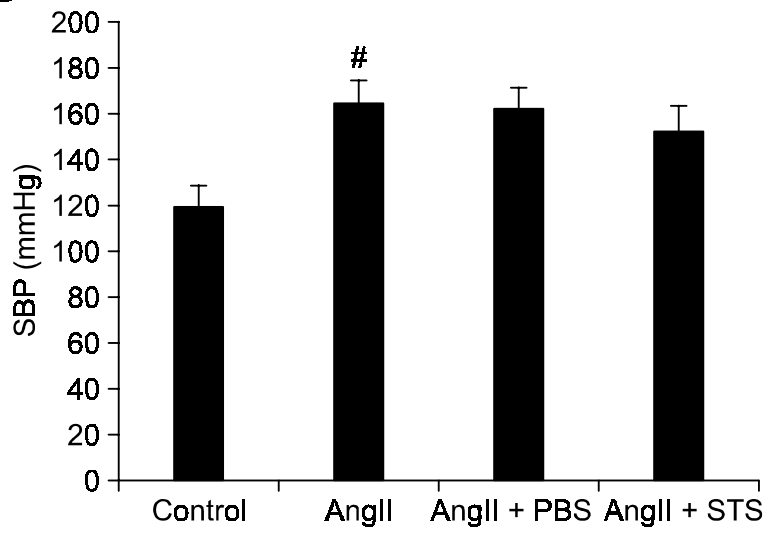

Figure 2. The LVW/BW ratio and SBP after the long term treatment. After 3 weeks of treatment, the LVW/BW ratio and the SBP were measured. Data represent means \pm S.D. $\# P<0.01$ versus control group; ${ }^{*} P<0.01$ versus Ang II group. The experiments were repeated five times with reproducible results.

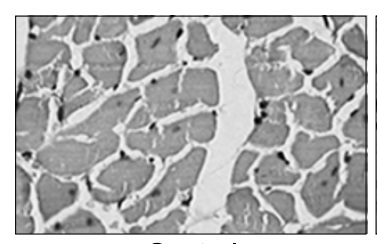

Control

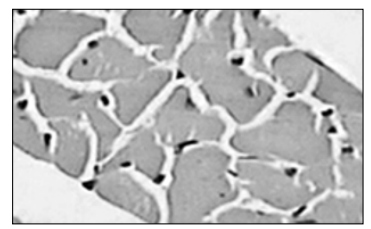

Angll + PBS

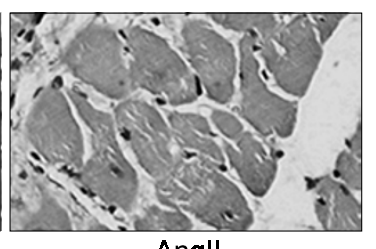
Angll

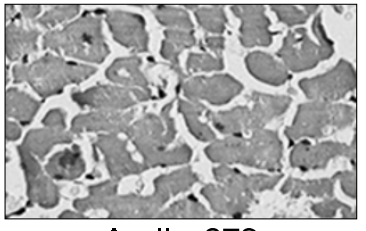

Angll + STS

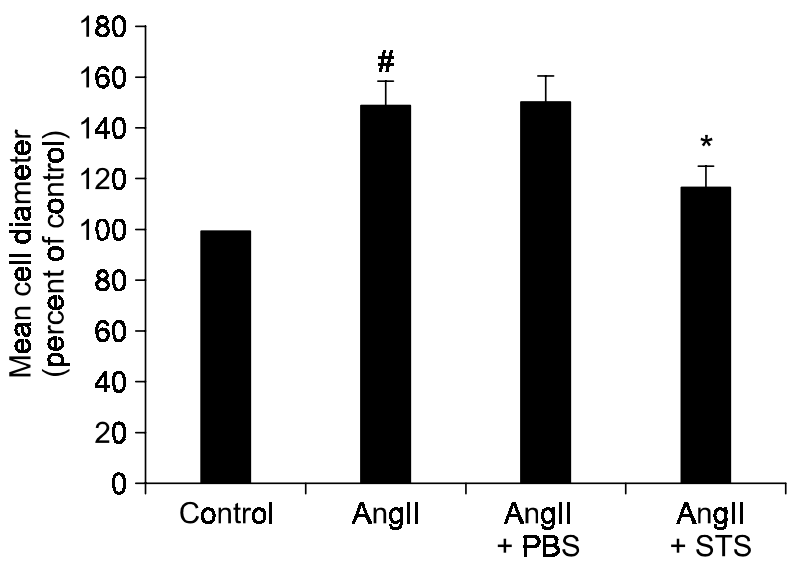

Figure 3. Long-term treatment of STS (50 mg/kg/d) inhibited Ang II-induced cardiomyocyte hypertrophy in vivo. Representative hematoxylin and eosin-stained high magnification (original magnification $\times 200$ ) of left ventricles from different groups. Mean myocyte diameter was calculated by measuring 100 cells from sections. Data represent means \pm S.D. \#P $<0.01$ versus control group; ${ }^{*} P<0.01$ versus Ang II group. The experiments were repeated six times with reproducible results.

\section{Effects of STS on the Ang II-induced cardiomyocyte hypertrophy}

In addition to increased LVW/BW ratio, cardiomyocyte hypertrophy is characterized by the increase in cell size, protein synthesis and induction of fetal-type genes (e.g., ANP). Therefore, we examined the effects of STS on these parameters. First, cardiomyocytes were treated with $0.1 \mu \mathrm{M}$ Ang II alone or with $10 \mu \mathrm{M}$ STS for $24 \mathrm{~h}$. Ang II induced a marked increase in cell size which was markedly inhibited by STS (Figure 4). Next, inhibition of Ang II-induced protein synthesis by treatment with STS was analyzed by measurement of $\left[{ }^{3} \mathrm{H}\right]$ Leucine incorporation into the cardiomyocytes. As shown in Figure 5 , exposure of cells to STS $(2,10,50 \mu \mathrm{M})$ for
$24 \mathrm{~h}$ significantly depressed Ang II-induced increases in $\left[{ }^{3} \mathrm{H}\right]$ Leucine incorporation. Furthermore, ANP mRNA expression was examined by Northern Blot. Results indicated Ang II induced expression of ANP gene in myocytes and the induction was markedly decreased by treatment with STS (Figure $5)$.

\section{Effect of STS on ERK activation}

We further investigated whether STS inhibited ERK pathway in Ang II-treated cardiomyocytes. To investigate effects of STS on ERK, myocytes were treated with $0.1 \mu \mathrm{M}$ Ang II alone or with STS $(2,10$, $50 \mu \mathrm{M})$ for $20 \mathrm{~min}$. The activation of ERK was examined by Western blot with the phosphospecific 


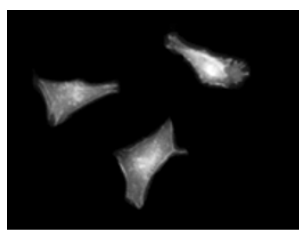

Control

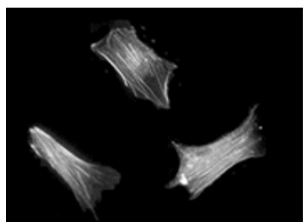

Angll + STS

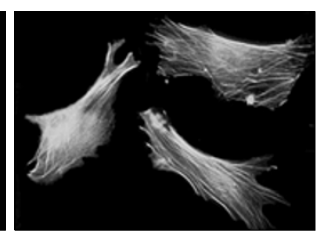

Angll

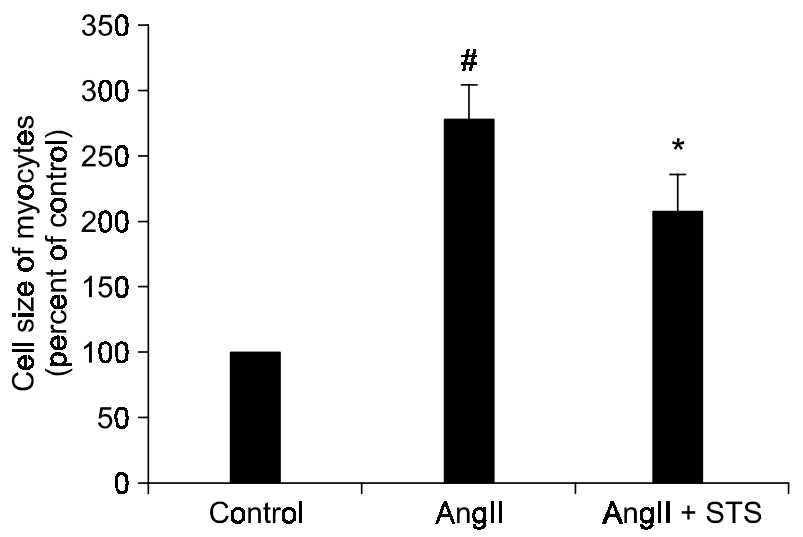

Figure 4. Inhibition of STS on Ang II-induced increase in the cell size. Cells were treated with $0.1 \mu \mathrm{M}$ Ang II alone or with $10 \mu \mathrm{M}$ STS for $24 \mathrm{~h}$. Immunofluorescence was performed with Texas Red-X pholloidin. The cell size of cardiomyocytes was measured by directly tracing actin-stained cardiomyocytes. $\# P<0.01$ versus control group; ${ }^{\star} P<0.01$ versus Ang II group. The experiments were repeated five times with reproducible results.
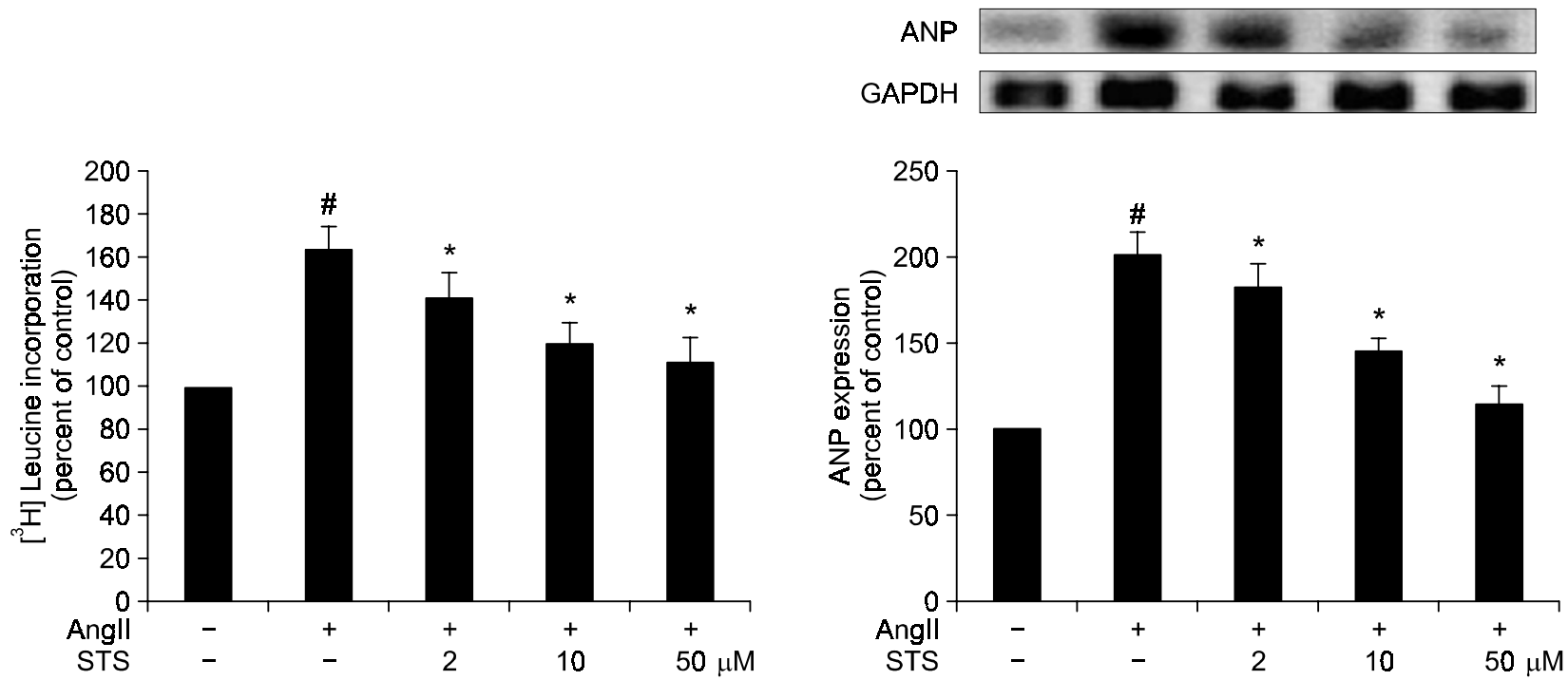

Figure 5. Inhibition of STS on Ang II-induced increase in $\left.{ }^{3} \mathrm{H}\right] \mathrm{Leucine}$ incorporation and ANP expression. Myocytes were treated with $0.1 \mu \mathrm{M}$ Ang II alone or with STS $(2,10,50 \mu \mathrm{M})$ for $24 \mathrm{~h}$. Protein synthesis rate was measured as $\left[{ }^{3} \mathrm{H}\right]$ Leucine incorporation. ANP mRNA expression was measured by Northern blot. Control group were treated with saline. $\# P<0.01$ versus control group; ${ }^{*} P<0.01$ versus Ang II group. The experiments were repeated five times with reproducible results.

antibody. The data suggest that STS markedly inhibited ERK $1 / 2$ activations with increasing dose of STS (Figure 6). Thus, STS inhibited the activations of ERK1/2 signaling pathway in a dose-dependent manner.

\section{Effect of STS on MEK activation}

MAPK/ERK kinase-1/2 (MEK1/2) phosphorylates and activates ERK1/2 in response to mitogenic stimuli (Solit et al., 2005). To elucidate the mechanism by which STS inhibited ERK activation, we examined effect of STS on MEK activation in cardiomyocytes. The protein content of $p-M E K 1 / 2$ was also examined by Western blot analysis. As shown in Figure 6, Ang II stimulation increased the activity of MEK1/2, which was inhibited by STS.

Moreover, to confirm the significance of MEK/ERK pathway in the anti-hypertrophic effect of STS, we examined the effects of MEK1/2 inhibitor U0126 (Favata et al., 1998) on hypertrophic response such as $\left[{ }^{3} \mathrm{H}\right]$ Leucine incorporation and ANP mRNA ex- 

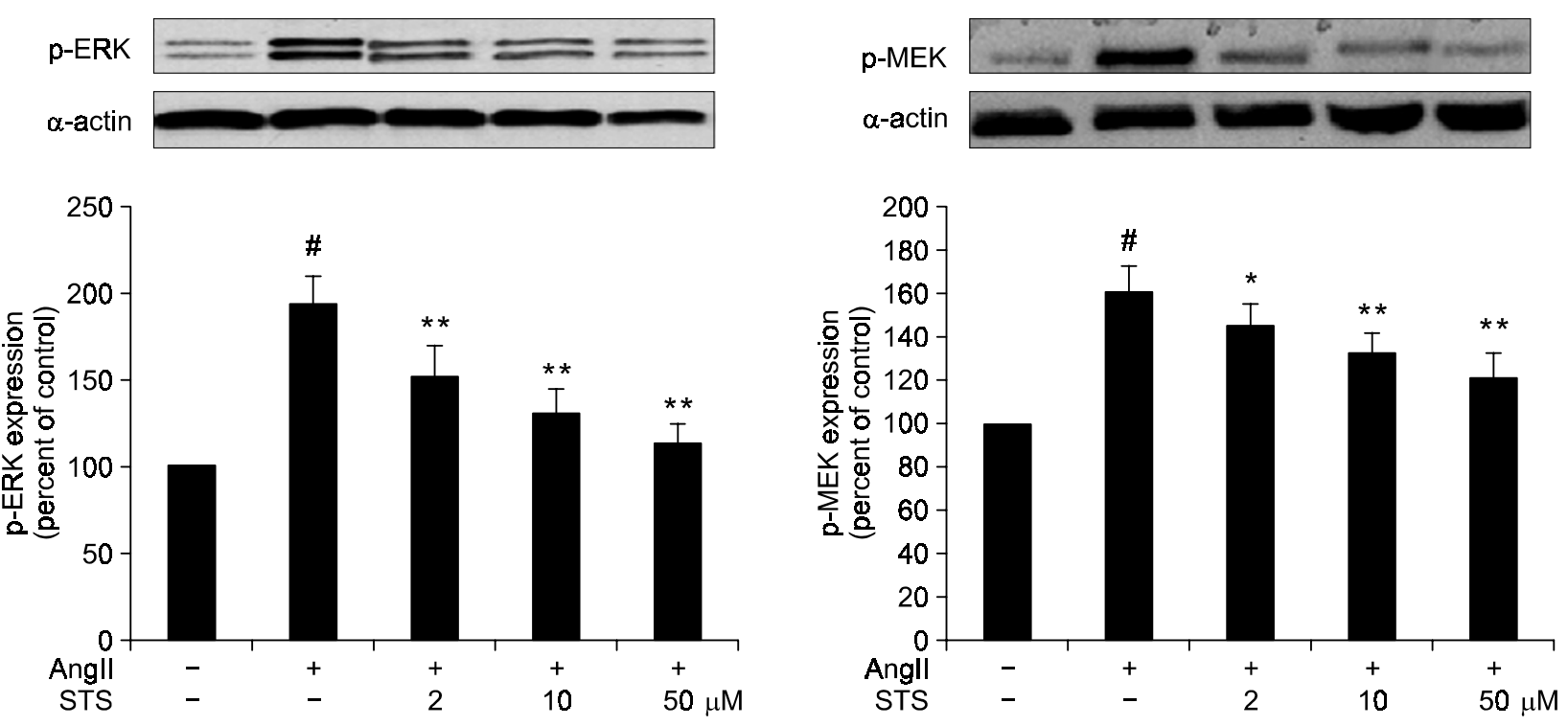

Figure 6. Inhibition of STS on Ang II-induced ERK and MEK activation. Myocytes were treated with $0.1 \mu \mathrm{M}$ Ang II alone or with STS $(2,10,50 \mu \mathrm{M})$ for $20 \mathrm{~min}$. The activations of ERK and MEK were examined by Western blot with the phosphospecific antibody. Data represent means \pm S.D. \#P< 0.01 versus control group; ${ }^{*} P<0.05$ and ${ }^{* *} P<0.01$ versus Ang II group. The experiments were repeated five times with reproducible results.
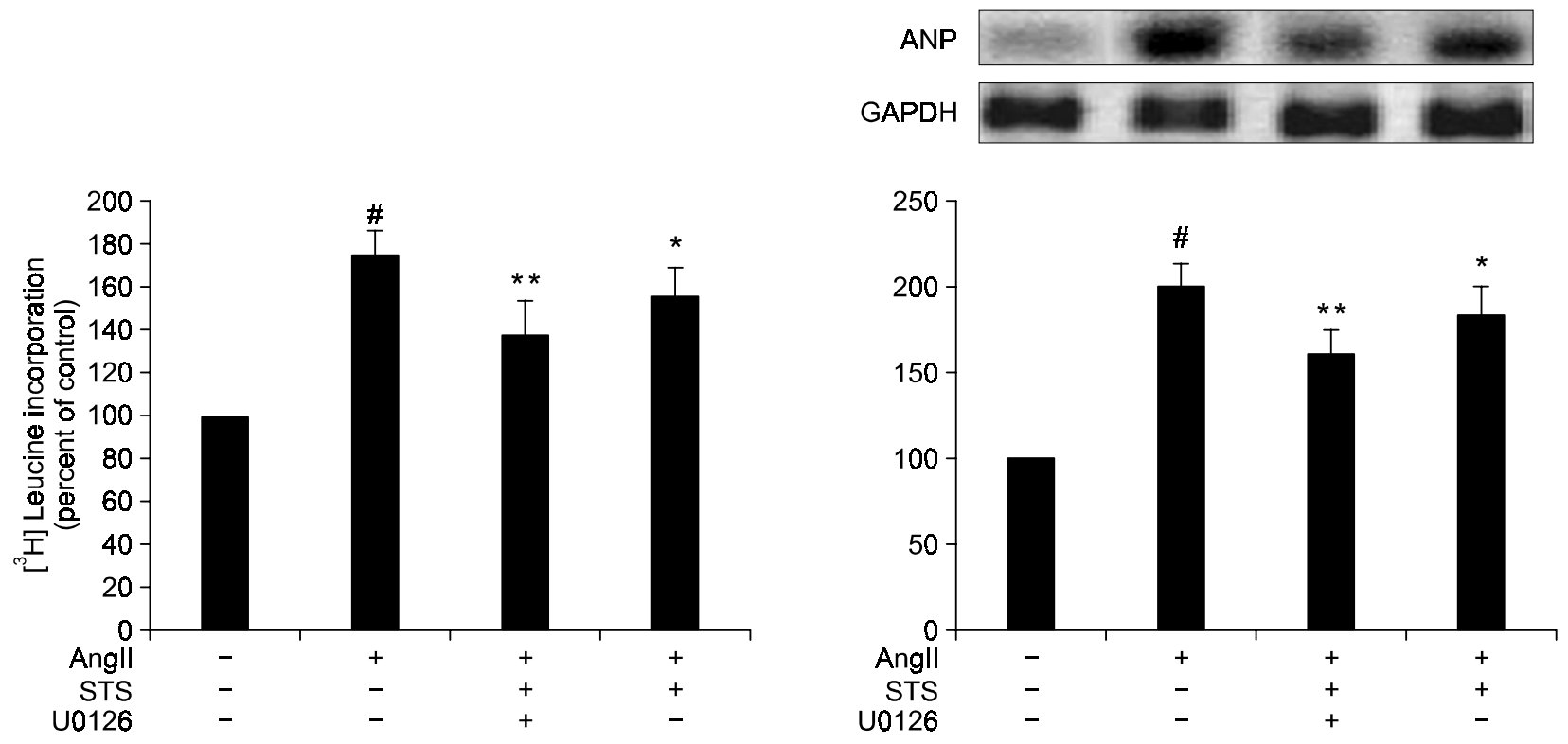

Figure 7. Inhibition of U0126 on STS-induced depressions of [ $\left.{ }^{3} \mathrm{H}\right]$ Leucine incorporation and ANP expression. U0126 was dissolved in DMSO. Control cultures were supplemented with DMSO vehicle alone ( $0.1 \%$ final concentration). In each group, concertration of Ang II was $0.1 \mu \mathrm{M}$ and that of STS was $10 \mu \mathrm{M}$. After myocytes were treated differently for $\left.24 \mathrm{~h},{ }^{3} \mathrm{H}\right]$ Leucine incorporation and ANP expression were measured. Data represent means \pm S.D. $\# P<0.01$ versus control group; ${ }^{*} P<0.01$ versus Ang $\|$ group and ${ }^{* *} P<0.05$ versus (Ang II + STS) group. The experiments were repeated five times with reproducible results.

pression. U0126 was dissolved in DMSO. Control cultures were supplemented with DMSO vehicle alone $(0.1 \%$ final concentration). In each group, concentration of Ang II was $0.1 \mu \mathrm{M}$ and that of STS was
$10 \mu \mathrm{M}$. After myocytes were treated differently for 24 $\mathrm{h},\left[{ }^{3} \mathrm{H}\right]$ Leucine incorporation and ANP mRNA expression were measured.

STS-induced depression in $\left[{ }^{3} \mathrm{H}\right]$ Leucine incor- 
poration was significantly enhanced by U0126 (20 $\mu \mathrm{M})$. Moreover, U0126 makedly enhanced STSinduced depression in ANP mRNA expression (Figure 7). These findings suggested the importance of MEK/ERK pathway in the anti-hypertrophic effects of STS.

\section{Discussion}

Cardiomyocyte hypertrophy refers to the increase of cell's volume and myocomma; and changes of types of contracting proteins at the same time. In its early stage, it is a compensatory response, but if prolonged, the heart may undergo a transition to heart failure. Therefore, it is important to prevent the process of cardiomyocyte hypertrophy induced by extracellular signals for any proposed therapy to regulate the myocardial hypertrophic responses (Cohn et al., 2000; Frey et al., 2004). As an important neuroendocrine factor, Ang II can not only regulate the physiological functions of cadiovascular system, but also make a vital role in physiopathologic processes such as myocardial hypertrophy or heart failure (Wassmann et al., 2004).

The root of Salvia miltiorrhiza Bunge, known as Danshen in Chinese, is a herbal plant widely used to cure myocarditis and myocardial infarction (Chen et al., 1979). Tanshinone IIA is the most abundant component and structurally representative of the tanshinones of Salvia miltiorrhiza (Tang and Eisenbrand, 1992). In China, Sodium tanshinone IIA sulfonate (STS), a derivative of tanshinone IIA, is usually administrated to patients suffering myocardial infarction and angina cordis (Chen et al., 1979; Tao et al., 1996). Although STS has been used as a medicinal agent in the treatment of many diseases, its role in cardiomyocyte hypertrophy remains unknown. Recently, tanshinone IIA was shown to be a promising new anti-hypertrophic drug that reduced cardiomyocyte hypertrophy (Takahashi et al., 2002). Nevertheless, up to date, little is known about the cellular and molecular mechanisms of STS-mediated anti-hypertrophic effects in cardiomyocytes after Ang II stimulation and no work has been done to investigate the effect of STS on the MEK/ERK pathway. In this study, we attempted to explore the possible anti-hypertrophic effect of STS on Ang II-induced cardiomyocyte hypertrophy and its molecular events.

In this research, in vivo, we used Ang II infused by mini-pump to establish cardiomyocyte hypertrophy. After our long-term treatment studies, STS markedly inhibited Ang II-induced increases in the LVW/BW ratio, independent of decreasing SBP (Figure 2). As previously reported, in vivo Ang II via $A T_{1}$ Receptor, causes not only ventricular hypertrophy, independently of blood pressure, but also a shift to the fetal phenotype of the myocardium (Lijnen and Petrov, 1999). Therefore, STS may have some pharmacological properties similar to angiotensin-converting enzyme inhibitors or Ang II receptor antagonists, which needs further research. Under microscope, the characteristic hypertrophic changes induced by Ang II were markedly inhibited by long-term treatment of STS (Figure 3). Furthermore, in cultured cardiomyocytes, STS significantly depressed Ang Il-induced marked increases in the cell size, protein synthesis and induction of ANP gene (Figure 4 and $5)$. Then we tried to explore the mechanism through which STS inhibited cardiomyocyte hypertrophy.

The mechanism underlying the attenuation of Ang II-induced actions by STS is an area of considerable interest. Several points in the Ang II signal transduction pathways are possible sites of STS action (Force and Bonventre, 1998; Miyazaki et al., 1998; Dostal and Baker, 1999). Although the mechanism by which Angll induces cardiomyocyte hypertrophy is not fully understood, protein kinases especially the MAPK family have been reported to play a pivotal role in the development of cardiac hypertrophy (Kim et al., 1999; Seko et al., 1999; Fischer et al., 2001; Takeishi et al., 2001). Among the MAPK superfamily, ERK1/2 has been focused on the essential regulators of a hypertrophic response although the role of JNK and p38 were recently studied in regulating cardiac hypertrophy (Sugden, 2001). ERK1/2 phosphorylation targets substrates in the nucleus (e.g. c-myc, c-jun, and ATF-2), leading to transcriptional reprogramming that is likely responsible, at least partly, for altered gene expression associated with hypertrophy. In agreement with previous findings (Shih et al., 2001), we found that Ang II enhanced ERK activation which was dramatically decreased after treatment with STS in a dose- dependent manner (Figure 6). This result demonstrates that inhibition of ERK1/2 pathway might be important for protective effects of STS. However, any site regulating ERK1/2 could also be implicated.

$M E K 1 / 2$, an immediate upstream regulator of ERK, phosphorylates and activates ERK1/2, but not JNK or p38 in response to Ang II stimulation (Solit et al., 2005). Transgenic overexpression of MEK $1 / 2$ results in considerable cardiac hypertrophy (Bueno et al., 2000). Our results indicated the inhibition pattern of MEK activation by STS was consistent with that of ERK1/2 activation, indicating that MEK/ ERK pathway plays a significant role in the antihypertrophic effect of STS (Figure 6). The signal cascade of angiotension-II coupling to ERK pathway was reported (Pinzar et al., 2005). In the paper, it was found that $10 \mu \mathrm{M}$ U0126 can completely abo- 
lishes ERK1/2 phosphorylation. As an inhibitor of MEK, U0126 was discovered in a screen for compounds that inhibited AP-1 dependent transcription, and was subsequently characterized as an inhibitor of both MEK1 and MEK2 (Favata et al., 1998). As the latest report, U0126 has marked anti-hypertrophic effects on cardiomyocyte hypertrophy and downregulated some hypertrophic gene expressions (Kennedy et al., 2006). U0126 also abolishes Prostaglandin $\mathrm{E}_{2}$-induced cardiac hypertrophy in a dosedependent manner (Frias et al., 2007). Furthermore, U0126 inhibits endothelin-1 and phenylephrine-induced protein synthesis and increased cell size, sarcomeric reorganization, and expression of beta-myosin heavy chain in myocytes (Yue et al., 2000). Therefore, to further elucidate the significance of MEK/ERK pathway in the anti-hypertrophic effect of STS, we examined the effect of U0126 on $\left[{ }^{3} \mathrm{H}\right]$ Leucine incorporation and ANP mRNA expression. STS-induced depressions in $\left[{ }^{3} \mathrm{H}\right]$ Leucine incorporation and ANP mRNA expression were largely enhanced by U0126 $(20 \mu \mathrm{M})$ (Figure 7). It was clearly shown that U0126 and STS affects synergeticlly. This finding confirms that MEK/ERK pathway plays a significant role in the anti-hypertrophic effect of STS. Nevertheless, we can not rule out the possibilities that some other mechanisms are also involved in the growth-inhibitory effects of STS in cardiomyocytes. Then the molecular mechanism underlying anti-hypertrophic effect of STS remains to be further explored.

Taken together, the present study delivers important new insights to the molecular mechanisms of action of STS on cardiomyocytes. Our results indicated that STS markedly depresses Ang II-induced cardiomyocyte hypertrophy in vivo and in vitro. The inhibition of MEK/ERK pathway may be involved in the anti-hypertrophic effect. It provides a possible mechanism mediating the inhibitory effect of STS on cardiomyocyte hypertrophy. Although the precise mechanism by which STS inhibits the development of cardiac hypertrophy remains to be further clarified, understanding the pharmacological actions of STS on cardiac cells may allow the development of novel therapeutic strategies for modulating the hypertrophy of cardiomyocytes and the overall remodeling of the myocardium. The next steps we need to take are to investigate the effects of STS on other mediators and effectors of cardiomyocyte hypertrophy.

\section{Acknowledgement}

This work was supported by grant 30500657 from the National Natural Science Foundation of China. The authors express their thanks to Prof. Jialing Wang in Department of Pharmacology for his generous technical supports.

\section{References}

Baker KM, Aceto JF. Angiotensin II stimulation of protein synthesis and cell growth in chick heart cells. Am J Physiol 1990;259:610-8

Bueno OF, De Windt LJ, Tymitz KM, Witt SA, Kimball TR, Klevitsky R, Hewett TE, Jones SP, Lefer DJ, Peng CF, Kitsis RN, Molkentin JD. The MEK1-ERK1/2 signaling pathway promotes compensated cardiac hypertrophy in transgenic mice. EMBO J 2000;19:6341-50

Chen W, Dong Y, Wang C, Ting G. Pharmacological studies of sodium tanshinone IIA sulfonate. Acta Pharmacol Sin 1979;14:277-83

Cohn JN, Ferrari R, Sharpe N. Cardiac remodeling-concepts and clinical implications: a consensus paper from an international forum on cardiac remodeling. Behalf on an international forum on cardiac remodelling. J Am Coll Cardiol 2000;35:569-82

Dostal DE, Baker KM. The cardiac renin-angiotensin system: conceptual, or a regulator of cardiac function? Circ Res 1999;85:643-50

Favata MF, Horiuchi KY, Manos EJ, Daulerio AJ, Stradley DA, Feeser WS, Van Dyk DE, Pitts WJ, Earl RA, Hobbs F, Copeland RA, Magolda RL, Scherle PA, Trzaskos JM. Identification of a novel mitogen inhibitor of mitogen-activated protein kinase kinase. J Biol Chem 1998;273:18623-32

Fischer TA, Ludwig S, Flory E, Gambaryan S, Singh K, Finn P, Pfeffer MA, Kelly RA, Pfeffer JM. Activation of cardiac c-Jun $\mathrm{NH}(2)$-terminal kinases and p38-mitogen-activated protein kinases with abrupt changes in hemodynamic load. Hypertension 2001;37:1222-8

Force T, Bonventre JV. Growth factors and mitogen-activated protein kinases. Hypertension 1998;31:152-61

Frey N, Katus HA, Olson EN, Hill JA. Hypertrophy of the heart: a new therapeutic target? Circulation 2004;109:1580-9

Frias MA, Rebsamen MC, Gerber-Wicht C, Lang U. Prostaglandin E2 activates Stat3 in neonatal rat ventricular cardiomyocytes: A role in cardiac hypertrophy. Cardiovasc Res 2007;73:57-65

Hannan RD, Luyken J, Rothblum LI. Regulation of ribosomal DNA transcription during contraction-induced hypertrophy of neonatal cardiomyocytes. J Biol Chem 1996;271:3213-20

Hayakawa $H$, Raij L. The link among nitric oxide synthase activity, endothelial function, and aortic and ventricular hypertrophy in hypertension. Hypertension 1997;29:235-41

Kagiyama S, Eguchi S, Inagami T, Zhang YC, Phillips MI. Angiotensin II-induced cardiac hypertrophy and hypertension are attenuated by epidermal growth factor receptor antisense. Circulation 2002;106:909-12

Kennedy RA, Kemp TJ, Sugden PH, Clerk A. Using U0126 to dissect the role of the extracellular signal-regulated kinase $1 / 2$ (ERK1/2) cascade in the regulation of gene expression by endothelin-1 in cardiac myocytes. J Mol Cell Cardiol 2006; 41:236-47

Kim L, Lee T, Fu J, Ritchie ME. Characterization of MAP kinase and PKC isoform and effect of ACE inhibition in hypertrophy 
in vivo. Am J Physiol 1999;277:1808-16

Levy D, Garrison RJ, Savage DD, Kannel WB, Castelli WP. Prognostic implications of echocardiographically determined left ventricular mass in the Framingham Heart Study. $\mathrm{N}$ Engl J Med 1990;322:1561-6

Lijnen P, Petrov V. Renin-Angiotensin System, Hypertrophy and Gene Expression in Cardiac Myocytes. J Mol Cell Cardiol 1999;31:949-70

Maller JL. Signal transduction: fishing at the cell surface. Science 2003;300:594-5

Miao CY, Tao X, Gong K, Zhang SH, Chu ZX, Su DF. Arterial remodeling in chronic sinoaortic-denervated rats. J Cardiovasc Pharmacol 2001;37:6-15

Miyazaki H, Shibata T, Fuji N. Intracellular signaling pathways of angiotensin II receptor type I involved in the development of cardiovascular diseases. Nippon Rinsho 1998;56:1906-11

Pinzar E, Wang T, Garrido MR, Xu W, Levy P, Bottari SP. Angiotensin II induces tyrosine nitration and activation of ERK1/2 in vascular smooth muscle cells. FEBS Letters 2005;579:5100-4

Ptashne M, Gann A. Signal transduction: imposing specificity on kinases. Science 2003;299:1025-7

Seko Y, Takahashi N, Tobe K, Kadowaki T, Yazaki Y. Pulsatile stretch activates mitogen-activated protein kinase (MAPK) family members and focal adhesion kinase (p125(FAK)) in cultured rat cardiac myocytes. Biochem Biophys Res Commun 1999;259:8-14

Sen S. Regression of cardiac hypertrophy. Experimental animal model. Am J Med 1983;75:87-93

Shih NL, Cheng TH, Loh SH, Cheng PY, Wang DL, Chen YS, Liu SH, Liew CC, Chen JJ. Reactive oxygen species modulate angiotensin II-induced beta-myosin heavy chain gene expression via Ras/Raf/extracellular signal-regulated kinase pathway in neonatal rat cardiomyocytes. Biochem Biophys Res Commun 2001;283:143-8

Solit DB, Garraway LA, Pratilas CA, Sawai A, Getz G, Basso A, Ye Q, Lobo JM, She Y, Osman I, Golub TR, Sebolt-Leopold J, Sellers WR, Rosen N. BRAF mutation predicts sensitivity to MEK inhibition. Nature 2005;439:358-62

Sugden $\mathrm{PH}$. Signalling pathways in cardiac myocyte hypertrophy. Ann Med 2001;33:611-22
Sven W, Georg N. The role of the AT1 receptor in the cardiovascular continuum. Eur Heart J Suppl 2004;6:h3-h9

Takahashi K, Ouyang X, Komatsu K, Nakamura N, Hattori M, Baba A, Azuma J. Sodium tanshinone IIA sulfonate derived from Danshen (Salvia miltiorrhiza) attenuates hypertrophy induced by angiotensin II in cultured neonatal rat cardiac cells. Biochem Pharmacol 2002;64:745-50

Takeishi Y, Huang Q, Abe J, Glassman M, Che W, Lee JD, Kawakatsu H, Lawrence EG, Hoit BD, Berk BC, Walsh RA. Src and multiple MAP kinase activation in cardiac hypertrophy and congestive heart failure under chronic pressure-overload: comparison with acute mechanical stretch. J Mol Cell Cardiol 2001;33:1637-48

Tang W, Eisenbrand G. Salvia miltiorrhiza Bge. Chinese drugs of plant origin, 1992, 891-902, Springer, Berlin, Germany

Tao J, Wang QZ, Liu QY. Experimental study on prevent effect of tanshinone on injury of ischemia-reperfusion of heart. Acta Anaesthesiol Sin 1996;16:202-4

Thorburn J, Carlson M, Mansour SJ, Chien KR, Ahn NG, Thorburn A. Inhibition of a signaling pathway in cardiac muscle cells by active mitogen-activated protein kinase kinase. Mol Biol Cell 1995;6:1479-90

Wassmann S, Nickenig G. The role of the AT1 receptor in the cardiovascular continnum. Eur Heart J 2004;6:h3-h9

Wollert KC, Studer R, von Bulow B, Drexler H. Survival after myocardial infarction in the rat. Role of tissue angiotensin-converting enzyme inhibition. Circulation 1994;90: 2457-67

Yamazaki T, Komuro I, Kudoh S, Zou Y, Shiojima I, Mizuno T, Takano H, Hiroi Y, Ueki K, Tobe K, Kadowaki T, Yazaki Y. Angiotensin II partly mediates mechanical stress-induced cardiac hypertrophy. Circ Res 1995;77:258-65

Yue TL, Gu JL, Wang C, Reith AD, Lee JC, Mirabile RC, Kreutz R, Wang Y, Maleeff B, Parsons AA, Ohlstein EH. Extracellular signal-regulated kinase plays an essential role in hypertrophic agonists, endothelin-1 and phenylephrine-induced cardiomyocyte hypertrophy. J Biol Chem 2000;275:37895-901

Zhao BL, Jiang W, Zhao Y, Hou JW, Xin WJ. Scavenging effects of Salvia miltiorrhiza on free radicals and its protection for myocardial mitochondrial membranes from ischemiareperfusion injury. Biochem Mol Biol Int 1996;38:1171-82 